\title{
CRESCIMENTO DE MUDAS DE MORINGA EM FUNÇÃO DA SALINIDADE DA ÁGUA E DA POSIÇÃO DAS SEMENTES NOS FRUTOS ${ }^{1}$
}

Francisco de Assis de Oliveira ${ }^{2}$, Mychelle Karla Teixeira de Oliveira $^{3}$, Ricardo Carlos Pereira da Silva ${ }^{3}$, Otaciana Maria dos Prazeres da Silva ${ }^{3}$, Priscila de Melo Evangelista Maia ${ }^{4}$ e Willame dos Santos Cândido ${ }^{5}$

\begin{abstract}
RESUMO - A escolha das sementes é de fundamental importância para a obtenção de mudas de qualidade, principalmente quando são produzidas sob condições ambientais adversas. Este trabalho foi desenvolvido com o objetivo de avaliar a influencia da salinidade sobre o desenvolvimento de mudas de moringa provenientes de sementes localizadas em diferentes posições no fruto. O delineamento utilizado foi o inteiramente casualizado, com os tratamentos arranjados em esquema fatorial 3 x 4 e quatro repetições. Os tratamentos resultaram da combinação de três posições de sementes no fruto (basal, mediana e apical) com quatro níveis de salinidade da água de irrigação $\left(0,5 ; 2,0 ; 3,5 ; \mathrm{e} 5,0 \mathrm{dS} \mathrm{m}^{-1}\right)$. Foram avaliadas as seguintes características de crescimento: altura (ALT), diâmetro do caule (DC), diâmetro da raiz principal (DRP), número de folhas (NF), área foliar (AF), massa seca da parte aérea (MSPA), massa seca do sistema radicular (MSR) e massa seca total (MST). Os dados foram submetidos à análise de variância pelo teste $\mathrm{F}$ e as médias, comparadas pelo teste de Tukey a 5\% de probabilidade, para o efeito da posição da semente no fruto; e por análise de regressão, para os dados provenientes da salinidade. Houve interação significativa na maioria das características avaliadas. A salinidade da água de irrigação diminuiu em todas as variáveis. As mudas provenientes de sementes localizadas na porção basal dos frutos foram mais afetadas pela salinidade da água de irrigação.
\end{abstract}

Palavras-chave: Moringa oleifera Lam, Estresse salino, Irrigação.

\section{GROWTH OF MORINGA SEEDLINGS AS FUNCTION OF SALINITY AND SEED POSITION IN THE FRUITS}

\begin{abstract}
Choosing seeds is crucial for obtaining good quality seedlings, especially when the seedlings are grown under adverse environmental conditions. This work was carried out to evaluate the influence of salinity on the development of moring a seedlings from seeds located at different positions in the pod. The design used in this study was a completely randomized design with treatments arranged in $3 \times 4$ factorial scheme, with four replications. The treatments resulted from a combination of three positions in the seed fruit (basal, median and apical) with four salinity levels of irrigation water $\left(0.5,2.0,3.5\right.$ and $\left.5.0 \mathrm{dS} \mathrm{m}^{-1}\right)$. The growth characteristics evaluated were the following: height (ALT), stem diameter $(A D)$, diameter of the root principal (DRP), number of leaves $(N L)$, leaf area $(L A)$, shoot dry mass $(S D M)$, root dry mass $(R D M)$ and total dry mass (MST). The data were submitted to analysis of variance by $F$ test and means were compared by the Tukey test at $5 \%$ of probability for the effect of seed position in the fruits, and to regression analysis
\end{abstract}

\footnotetext{
${ }^{1}$ Recebido em 21.11.2010 aceito para publicação em 17.01.2013

${ }^{2}$ Universidade Federal Rural do Semi-Árido (UFERSA), Departamento de Ciências ambientais e Tecnológicas, Mossoró, RN. E-mail:<thikaoamigao@ufersa.edu.br>.

${ }^{3}$ Pós-graduação em Fitotecnia, UFERSA. E-mail: <mkto10@hotmail.com>, <ricarlos_agro@hotmail.com>e <otaciana_silva@yahoo.com.br>.

${ }^{4}$ Pós-graduação em Irrigação e Drenagem, UFERSA. E-mail: <pryscillademaia@ yahoo.com.br>.

${ }^{5}$ Pós-graduação em Genética e Melhoramento de Plantas, UNESP, Jaboticabal. E-mail: <Will_candido_ce@ @otmail.com>.
} 


\begin{abstract}
for data from the salinity. Interaction was significant for most traits. The salinity of irrigation water caused a reduction in all variables. Seedlings from seeds located in the basal portion of the fruits are more affected by salinity of irrigation water.
\end{abstract}

Keywords: Irrigation, Moringa oleifera Lam, Saline estresse.

\section{INTRODUÇÃO}

A moringa (Moringa oleifera Lam) é uma espécie de origem indiana que se tem adaptado satisfatoriamente às condições edafoclimáticas do semiárido do Nordeste brasileiro. Pode ser explorada tanto em condições irrigadas quanto de sequeiro, apresentando grande potencial em face de sua multiplicidade de usos alimentar, agrícola, medicinal e industrial (LORENZI; MATOS, 2002). Por não ser espécie explorada comercialmente, a moringa é uma espécie ainda pouco estudada, principalmente quanto ao seu crescimento em condições de estresse ambiental.

Além de fatores bióticos, como a qualidade das sementes utilizadas, o crescimento inicial das plantas pode ser influenciado por vários fatores abióticos. Entre esses fatores, a água é de extrema importância, pois, de acordo com Carvalho e Nakagawa (2000), ela não é apenas o primeiro fator que inicia a germinação. Em todas as demais etapas do metabolismo subsequente, há sua participação nas reações enzimáticas e na solubilização e transporte de metabólitos e como reagente na digestão hidrolítica de proteínas, carboidratos e lipídeos dos tecidos de reserva da semente.

Na literatura são escassos estudos enfocando o crescimento da moringa sob condições de estresse salino, como os desenvolvidos por Benedito et al. (2008) e Oliveira et al. (2009), os quais verificaram que a salinidade afeta consideravelmente a germinação e crescimento inicial das plântulas.

Estudos têm demonstrado que a escolha da semente é fundamental para a produção de mudas mais vigorosas, tanto na fase de mudas quanto na fase de pós-plantio. O tamanho da semente é um dos fatores que podem afetar o vigor das mudas, visto que possivelmente sementes de maiores dimensões apresentem maior quantidade de reservas nos seus cotilédones e, consequentemente, maior crescimento das plântulas, garantindo maior possibilidade de sucesso na formação da muda (NIETSCHE et al., 2004).

Revista Árvore, Viçosa-MG, v.37, n.1, p.79-87, 2013
De acordo com Munizzi et al. (2010), sementes de alto vigor apresentam maior velocidade nos processos metabólicos, propiciando emissão mais rápida e uniforme da raiz primária no processo de germinação e maior taxa de crescimento, produzindo plântulas com maiores dimensões.

Sementes maiores ou de maior densidade em uma mesma espécie são, potencialmente, mais vigorosas do que as menores e menos densas e originam plântulas com maior crescimento (CARVALHO; NAKAGAWA, 2000). Bezerra et al. (2004), avaliando a germinação e vigor de plântulas de moringa, constataram que sementes com maiores pesos apresentaram maior porcentagem e velocidade de germinação e geraram plântulas mais vigorosas, em confronto com as sementes leves. No entanto, a influência do peso da semente sobre a qualidade fisiológica das sementes pode variar em função da variabilidade genética da espécie estudada, conforme resultados obtidos por Zuchi et al. (2010), que, trabalhando com sementes de cultivares de mamona de maiores dimensões, constataram respostas diferentes, de acordo com cada cultivar. Biruel et al. (2010), avaliando a qualidade fisiológica em sementes de Caesalpinia leiostachya (Benth.) Ducke (pau-ferro) em função do tamanho e forma das sementes, verificaram que as sementes arredondadas tiveram maior espessura e melhor qualidade fisiológica.

Outro fator importante é a posição da semente na planta e, ou, no fruto, pois cada fruto, ou semente, de uma mesma planta pode ser formado em condições edafoclimáticas diferentes (MARCOS FILHO, 2005). Kikuti et al. (2003) constataram que o vigor de plântulas de milho, provenientes de sementes localizadas na base e terço médio da espiga, apresentou maior vigor em relação às sementes localizadas no ápice.

Diante do exposto, este trabalho foi desenvolvido com o objetivo de avaliar a influência da posição das sementes em fruto da moringa como alternativa para amenizar o possível efeito deletério da salinidade sobre o desenvolvimento das mudas. 


\section{MATERIAL E MÉTODOS}

O experimento foi conduzido no período de fevereiro a abril de 2009, em casa de vegetação do Departamento de Ciências Vegetais da Universidade Federal Rural do Semiárido (UFERSA), localizado no Município de Mossoró, RN, conforme as coordenadas geográficas de $5^{\circ} 11^{\prime} 31^{\prime \prime}$ de latitude Sul e $37^{\circ} 20^{\prime} 40^{\prime \prime}$ de longitude Oeste de Greenwich e com altitude média de $18 \mathrm{~m}$.

A estrutura da casa de vegetação é de aço galvanizado, sendo as partes laterais e frontais confeccionadas com tela negra com $50 \%$ de sombreamento. A cobertura é em arco tipo túnel, medindo 7,0 $\mathrm{m}$ de largura por 18,0 $\mathrm{m}$ de comprimento, com manta de polietileno de baixa densidade e transparente, com $0,15 \mathrm{~mm}$ de espessura.

As sementes de moringa (Moringa oleifera Lam.) utilizadas no ensaio foram colhidas no dia 15 de fevereiro de 2009, em uma planta do Campus da UFERSA, localizada em Mossoró, RN. Após a colheita, as sementes foram acondicionadas em sacos plásticos e transportadas para o Laboratório de Irrigação e Salinidade dessa universidade. $\mathrm{Na}$ amostra de trabalho, procedeu-se à separação das sementes em três classes, considerando a sua posição nos frutos e pesadas, obtendo-se os seguintes valores: basal (250,5 g. 1000-1 sementes), mediana (262,2 g. 1000 sementes) e apical (253,5 g. 1000 ${ }^{-1}$ sementes).

Como substrato, foi coletada uma amostra média de um Latossolo Vermelho-Amarelo de textura arenosa, coletado na camada de 0-30 m de profundidade, em área não cultivada localizada no Campus da UFERSA. Uma subamostra foi retirada, seca ao ar, peneirada em malha de 2 mm e submetida a análises físico-químicas (EMBRAPA, 1997), apresentando as seguintes características: $\mathrm{CE}=0,70 \mathrm{dS} \mathrm{m}{ }^{-1}, \mathrm{pH}=5,90 ; \mathrm{Ca}^{2+}=0,40$; $\mathrm{Mg}^{2+}=0,20 ; \mathrm{K}^{+}=0,14 ; \mathrm{Na}^{+}=0,11 ; \mathrm{Al}=0,00\left(\mathrm{cmol}_{\mathrm{c}} \mathrm{L}^{-1}\right) ; \mathrm{e}$ $\mathrm{P}=35,61\left(\mathrm{mg} \mathrm{dm}^{-3}\right)$.

O substrato foi peneirado em malha de $2 \mathrm{~mm}$ e acondicionado em vasos plásticos com capacidade para $3 \mathrm{dm}^{3}$, deixando-se cerca de $2 \mathrm{~cm}$ entre a superfície do solo e a borda superior do vaso para facilitar a irrigação.

Foram colocadas cinco sementes em caso vaso, a uma profundidade de $2 \mathrm{~cm}$; e cinco dias após a emergência das plântulas foi realizado o desbaste, deixando-se em cada vaso a plântula mais vigorosa. Um dia após o desbaste, deu-se início à aplicação de água salina, de acordo com os tratamentos.
O delineamento experimental utilizado foi o inteiramente casualizado, arranjados em esquema fatorial $3 \times 4$, com quatro repetições, sendo a unidade experimental representada por um vaso com capacidade para $3 \mathrm{dm}^{3}$ contendo uma plântula, de forma que ao todo foram utilizados 48 vasos. Os tratamentos resultaram da combinação de três tipos de sementes, conforme a localização nos frutos (basal, mediana e apical) com quatro níveis de salinidade da água de irrigação $(0,5$; 2,0; 3,5; e 5,0 dS m ${ }^{-1}$. A escolha desses níveis de salinidade deve-se às condutividades elétricas apresentadas pelas águas disponíveis para irrigação na região.

A água de menor nível salino $\left(0,5 \mathrm{dS} \mathrm{m}^{-1}\right)$ foi obtida no sistema de abastecimento do Campus da UFERSA e apresentou as seguintes características químicas: $\mathrm{pH}=8,30 ; \mathrm{CE}=0,50 \mathrm{dS} \mathrm{m}{ }^{-1} ; \mathrm{Ca}^{2+}=3,10 ; \mathrm{Mg}^{2+}=1,10 ; \mathrm{K}^{+}=0,30$; $\mathrm{Na}^{+}=2,30 ; \mathrm{Cl}^{-}=1,80 ; \mathrm{HCO}_{3}^{-}=3,00 ; \mathrm{eCO}_{3}^{2-}=0,20\left(\mathrm{mmol}_{\mathrm{c}} \mathrm{L}^{-1}\right)$. Os demais níveis salinos foram obtidos pela dissolução de cloreto de sódio $(\mathrm{NaCl})$ em água proveniente do sistema de abastecimento desse mesmo Campus, ajustando-se com condutivímetro de bancada, com correção automática da temperatura.

Aos 60 dias após a semeadura, as plantas foram coletadas, tendo-se o cuidado de retirar todas as raízes mediante lavagem em água corrente, mediante o uso de uma peneira para separar as raízes do substrato, e foram separadas em partes (raiz, caule, folhas) e analisadas quanto às seguintes características: altura (ALT), diâmetro do caule (DC), comprimento da raiz principal (DRP), número de folhas (NF), área foliar (AF), massa seca da parte aérea (MSPA), do sistema radicular (MSR), total (MST) e razão MSR/MSPA.

$\mathrm{Na}$ avaliação do número de folhas, foram contabilizadas apenas aquelas que apresentavam mais de $70 \%$ com coloração verde, visto que um dos sintomas característicos da resposta das plantas à salinidade é a presença de folhas necrosadas. Para determinação da área foliar (AF), foi utilizado o integrador de área, modelo LI-3100 da Licor. O tubérculo de cada planta foi limpo logo após a colheita, utilizando-se um pano; em seguida, o tubérculo foi separado da raiz; e, em balança de precisão $(0,01 \mathrm{~g})$, determinou-se a massa fresca da raiz (MFR). Para determinação da massa seca (MSR), as plantas foram acondicionadas em sacos de papel e postas para secar em estufa de circulação forçada, na temperatura de $70^{\circ} \mathrm{C} \pm 1{ }^{\circ} \mathrm{C}$, até atingir peso constante.

Revista Árvore, Viçosa-MG, v.37, n.1, p.79-87, 2013 
Os dados foram submetidos à análise estatística pelo teste $\mathrm{F}$, e as médias provenientes dos tipos de sementes foram comparadas pelo teste de Tukey a $5 \%$ de probabilidade. O efeito da salinidade foi analisado através de análise de regressão, ajustando-se os dados a modelos matemáticos que apresentaram maior grau de significância, sendo considerada, ainda, a resposta biológica das plantas à salinidade.

\section{RESULTADOS}

Houve interação significativa entre a posição da semente no fruto e os diferentes níveis de salinidade da água de irrigação para altura das plantas, área foliar e massa seca da parte aérea, das raízes e total a uma significância de $1 \%$ de probabilidade. Para número de folhas, foi observado efeito isolado dos fatores, sendo significativo a $5 \%$ de probabilidade para posição da semente e de $1 \%$ para salinidade, enquanto para diâmetro do caule, diâmetro e comprimento da raiz principal houve efeito significativo apenas para salinidade, a uma significância de $1 \%$ de probabilidade.

Não houve efeito da posição das sementes, com referência a área foliar (AF), diâmetro do caule (DC) e diâmetro da raiz principal (DRP), sendo obtidos valores médios de $368,33 \mathrm{~cm}^{2}$ planta $^{-1}, 0,61 \mathrm{~cm}$ e $1,66 \mathrm{~cm}$, respectivamente. Para as demais variáveis foram observados os menores valores nas plantas provenientes de sementes da posição mediana, embora para número de folhas (NF) não tenha diferido da semente da posição apical e da massa seca das raízes (MSR), que não diferiu da semente basal (Tabela 1).
Plantas com maior altura foram obtidas com uso da água de menor salinidade, e os maiores valores foram obtidos nas plantas oriundas de sementes retiradas da posição basal do fruto, com altura de $41,5 \mathrm{~cm}$, enquanto nas demais posições não ocorreu diferença significativa, com altura média de $34,79 \mathrm{~cm}$.

Em todas as posições das sementes houve redução linear da altura das plantas em função do aumento da salinidade, no entanto as sementes oriundas das posições mediana e apical apresentaram redução linear em cerca de 4,28 e 4,18 cm, para cada incremento unitário da salinidade e redução total de 56,28 e 53,20\%, respectivamente, para salinidade de $5,0 \mathrm{dS} \mathrm{m} \mathrm{m}^{-1}$, em comparação com as plantas irrigadas com água de salinidade de $0,5 \mathrm{dS} \mathrm{m}^{-1}$.

Nas sementes oriundas da parte basal do fruto ocorreu redução na ordem de $6,04 \mathrm{~cm}$ por incremento unitário da salinidade e redução total de $65,49 \%$ na maior salinidade $\left(5,0 \mathrm{dS} \mathrm{m}^{-1}\right)$, conforme mostrado na Figura $1 \mathrm{~A}$.

A área foliar das plantas foi reduzida com o aumento da salinidade, independente das posições das sementes. O grau de tolerância variou conforme a posição da semente no fruto, de forma que foram ajustadas equações de regressão para cada semente. Para as três posições estudadas foram ajustadas equações lineares decrescentes, tendo-se constatado que as sementes localizadas nas partes basal e apical do fruto apresentaram maior sensibilidade à salinidade. Para as sementes da posição basal, verificou-se que o aumento unitário da salinidade provocou redução de aproximadamente $16,9 \%$ na $\mathrm{AF}$, com perda total de $76,44 \%$ na maior

Tabela 1 - Número de folhas (NF), área foliar (AF), altura (ALT), diâmetro do caule (DC), diâmetro da raiz principal (DRP), massa seca das raízes (MSR), massa seca da parte aérea (MSPA) e massa seca total (MST) de mudas de moringa produzidas com sementes de diferentes posições nos frutos.

Table 1 - Number of leaves (NL), leaf area (LA), height (HEI), stem diameter (SD), diameter of main root (DRP), root dry mass (RDM), shoot dry mass (SDM) and total dry matter (TDM) of moringa seedlings grown from seeds in different positions in the fruits.

\begin{tabular}{|c|c|c|c|c|c|c|c|c|}
\hline Tipos de sementes & $\mathrm{NF}$ & $\mathrm{AF}$ & ALT & $\mathrm{DC}$ & DRP & MSR & MSPA & MST \\
\hline & \multicolumn{3}{|c|}{$\left(\mathrm{cm}^{2}\right.$ planta $\left.^{-1}\right)$} & \multicolumn{2}{|c|}{$(\mathrm{cm})-$} & 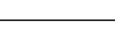 & planta & \\
\hline Basal & $9,8 \mathrm{a}^{*}$ & $273,2 \mathrm{a}$ & 27,9 a & $0,62 \mathrm{a}$ & $1,61 \mathrm{a}$ & $1,81 \mathrm{ab}$ & $2,10 \mathrm{a}$ & 3,91 a \\
\hline Mediana & $9,0 \mathrm{~b}$ & $267,7 \mathrm{a}$ & $24,6 \mathrm{~b}$ & 0,58 a & $1,67 \mathrm{a}$ & $1,63 \mathrm{~b}$ & $1,76 \mathrm{~b}$ & $3,39 \mathrm{~b}$ \\
\hline Apical & $9,7 \mathrm{ab}$ & 264,1 a & 25,9 a & $0,63 \mathrm{a}$ & $1,71 \mathrm{a}$ & $1,95 \mathrm{a}$ & $2,14 \mathrm{a}$ & 4,09 a \\
\hline $\mathrm{CV}(\%)$ & 9,8 & 8,7 & 8,1 & 13,3 & 6,0 & 16,8 & 18,3 & 11,6 \\
\hline
\end{tabular}

*Médias seguidas pelas mesmas letras nas colunas não diferem entre si, pelo teste de Tukey a 5\% de probabilidade.

Revista Árvore, Viçosa-MG, v.37, n.1, p.79-87, 2013 
salinidade. Na posição apical, houve redução de 15,6\% na AF em função do aumento unitário da salinidade e redução total de $70,56 \%$. Nas plantas oriundas de sementes localizadas na parte mediana dos frutos, verificou-se diminuição de $13,63 \%$ por incremento de $1,0 \mathrm{dS} \mathrm{m}^{-1}$ na água de irrigação e redução total em cerca de $61,33 \%$ na salinidade de $5,0 \mathrm{dS} \mathrm{m} \mathrm{m}^{-1}$, em comparação com as plantas irrigadas com água de menor nível salino (Figura 1B).

Para o número de folhas (NF), diâmetro do caule (DC) e diâmetro da raiz principal (DRP), foram observados efeitos deletérios e semelhantes da salinidade para
A.

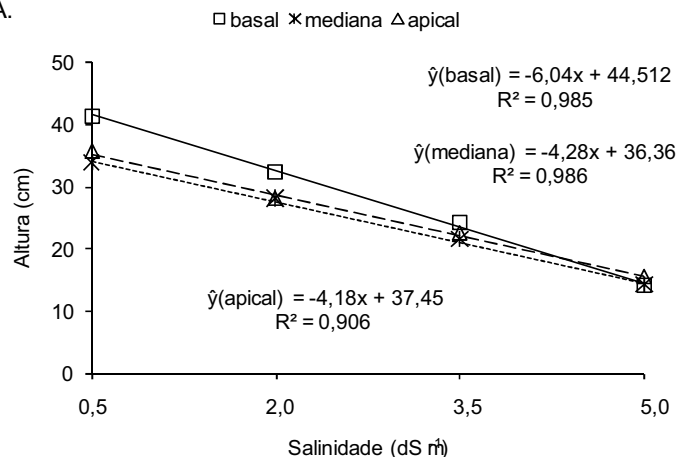

C.

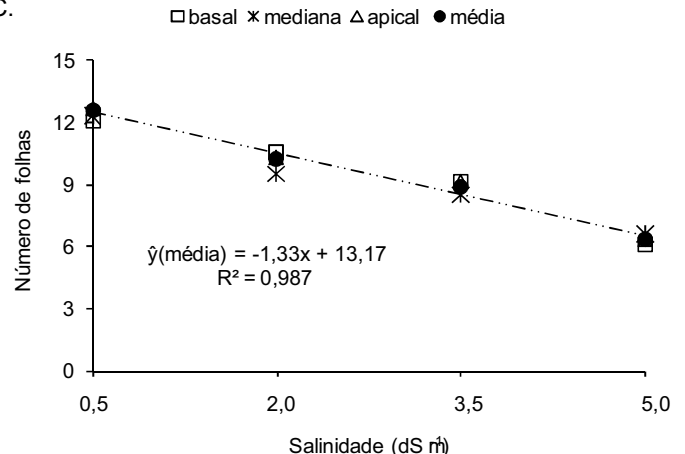

B.

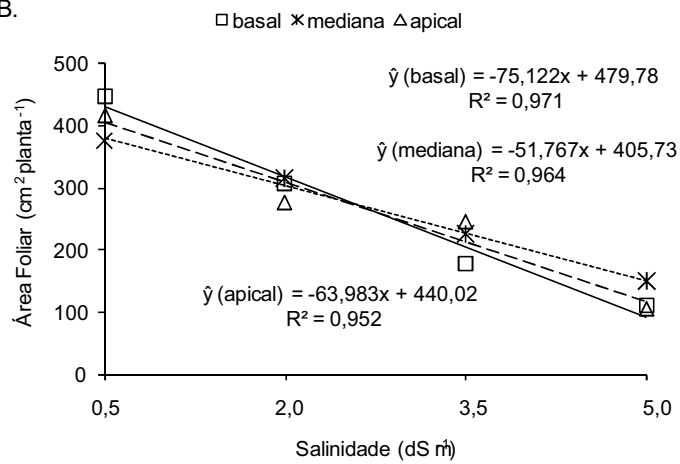

D.

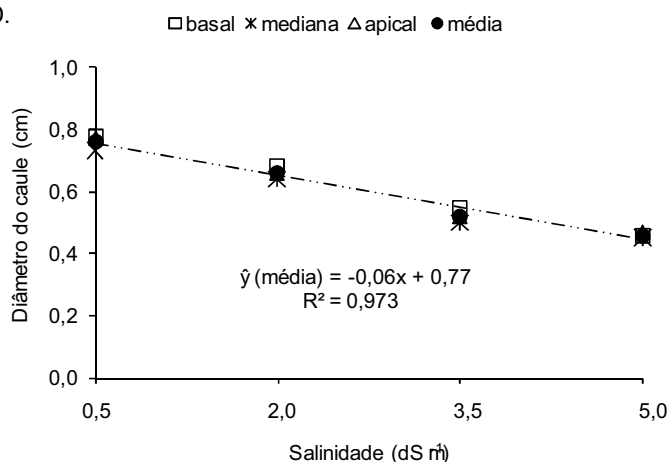

E.

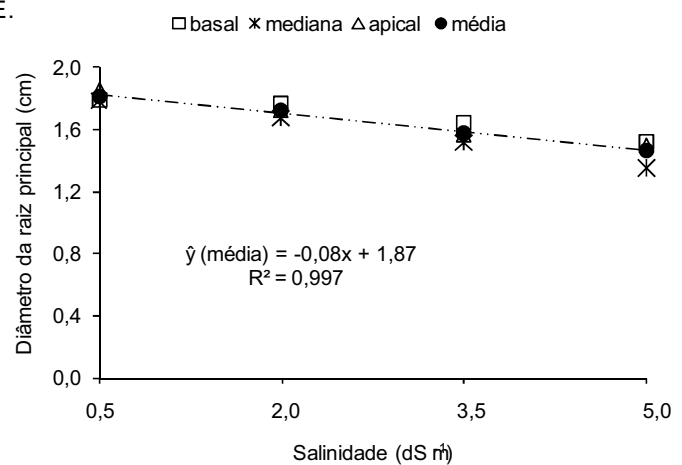

Figura 1 - Altura (A), área foliar (B), número de folhas (C), diâmetro do caule (D) e diâmetro da raiz principal (E) de mudas de moringa produzidas com sementes de diferentes posições no fruto e irrigadas com águas de diferentes níveis de salinidade (- basal, …mediana, ——apical, -“-”média).

Figure 1 - Height (A), leaf area $(B)$, number of leaves $(C)$, stem diameter $(D)$ and diameter of the main root $(E)$ of moringa seedlings grown from seeds at different positions in the fruit, and irrigated with water at different salinity levels

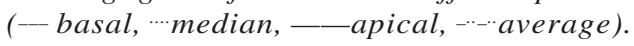


as três posições das sementes, de forma que foi ajustada apenas uma equação de regressão para as posições em cada uma dessas variáveis. Para as três variáveis foram ajustadas equações lineares e decrescentes, sendo observadas reduções médias de 1,33 (10,64\%) folha por planta, de $0,06 \mathrm{~cm}(8,10 \%)$ e $0,08 \mathrm{~cm}(4,40 \%)$ por aumento unitário da condutividade elétrica na água de irrigação, para diâmetro do caule e da raiz principal, respectivamente, e reduções totais de $47,86 \%$ para NF, $36,49 \%$ para DC e $19,67 \%$ para DRP nas plantas irrigadas comágua de salinidade de 5,0 dS m${ }^{-1}$, em comparação com aquelas irrigadas com água de nível salino de $0,5 \mathrm{dS} \mathrm{m} \mathrm{m}^{-1}$ (Figura 1C-E).

A massa seca das raízes foi afetada pela salinidade da água de irrigação, no entanto a resposta também variou de acordo com a posição das sementes nos frutos. Para as sementes das posições basal e mediana, os maiores valores foram estimados para as salinidades de 0,80 e 2,11 dS m${ }^{-1}$, com massa seca de 2,71 e 2,20 $\mathrm{g} \mathrm{planta}^{-1}$, respectivamente, enquanto os menores valores foram estimados para a salinidade de 5,0 dS m ${ }^{-1}$, na qual foram obtidos valores de 1,16 e 1,03 g planta $^{-1}$, resultando, assim, em redução total de $57,26 \%$ para a semente basal e de $53,22 \%$ para a semente mediana. Para as sementes da posição apical foi observada redução em cerca de $0,43 \mathrm{~g} \mathrm{planta}^{-1}$ por aumento unitário da condutividade elétrica da água de irrigação, de tal forma que na maior salinidade houve redução total de 62,12\% (Figura 2A).

Para massa seca da parte aérea também houve resposta variada de acordo com a posição das sementes, sendo maior nas plântulas oriundas das sementes da posição basal e na menor salinidade $\left(0,5 \mathrm{dSm}^{-1}\right)$, com $3,64 \mathrm{~g} \mathrm{planta}^{-1}$, enquanto na salinidade de $5,0 \mathrm{dS} \mathrm{m}^{-1}$ foi observado $0,56 \mathrm{~g} \mathrm{planta}^{-1}$, correspondendo, assim, em redução total de $84,63 \%$. Para as plantas originadas de sementes da posição mediana, os valores de massa seca reduziram com o aumento da salinidade, resultando em perda total de 74,55\% na maior salinidade. Já para as sementes da posição apical houve resposta positiva à salinidade até o nível de $1,5 \mathrm{dS} \mathrm{m}^{-1}$, com massa seca de 2,43 g planta $^{-1}$, decrescendo a partir deste, de forma que na maior salinidade foi verificado o menor valor, com massa seca de $0,77 \mathrm{~g}_{\text {planta }}{ }^{-1}$, o que corresponde à redução de 68,35\%, em comparação com a salinidade de $1,5 \mathrm{dS} \mathrm{m}^{-1}$ (Figura 2B).

Avaliando a massa seca total, verificou-se que nas sementes das posições basal e apical foram observadas reduções lineares, sendo verificadas

Revista Árvore, Viçosa-MG, v.37, n.1, p.79-87, 2013 reduções em cerca de 10,4 e 0,87 $\mathrm{g} \mathrm{planta}^{-1}$, respectivamente, por aumento unitário da salinidade, acarretando diminuição total de 75,24\% em sementes da posição basal e de $66,08 \%$ nas da posição apical. Nas da posição mediana, a massa seca total das plantas foi reduzida significativamente na salinidade a partir de $3,5 \mathrm{dS} \mathrm{m}^{-1}$, na qual foram obtidos cerca de 3,16 $\mathrm{g} \mathrm{planta}^{-1}$, enquanto na salinidade de $5,0 \mathrm{dS} \mathrm{m}^{-1}$ foram observados os menores valores $\left(1,75 \mathrm{~g} \mathrm{planta}^{-1}\right)$, correspondendo, assim, à redução de 44,62\% (Figura 2C).

A relação entre massa seca das raízes e massa seca da parte aérea (MSR/MSPA) foi influenciada pela salinidade da água de irrigação. Nas plantas oriundas de sementes das posições basal e mediana, as maiores relações MSR/MSPA foram obtidas na menor salinidade (1,34 e 1,33, respectivamente), decrescendo em seguida com o aumento do estresse salino. No entanto, foi constatada tendência de estabilização nas maiores salinidades, sendo observada ainda que, na maior salinidade, as sementes oriundas da posição mediana apresentaram maior relação MSR/ MSPA $(0,70)$. Nas sementes da posição apical foi observada resposta diferente das demais, de forma que a relação MSR/MSPA apresentou pouca variação em resposta à salinidade, variando de 0,90 a 0,79 , em salinidades de 0,5 e $5,0 \mathrm{dS} \mathrm{m}^{-1}$, respectivamente (Figura 2D). Esses resultados indicaram que, nas sementes das posições basal e mediana, a MSR foi mais afetada que a MSPA, fato esse que não ocorreu na semente apical.

\section{DISCUSSÃO}

Provavelmente, a diferença encontrada quanto ao tipo de sementes se deve ao suprimento de assimilados durante o desenvolvimento das sementes, visto que, segundo Marcos Filho (2005), as sementes localizadas na base dos frutos estão mais próximas da fonte fotossintética, em relação àquelas localizadas mais distantes do pedúnculo. Assim, as sementes da posição basal podem apresentar maior acúmulo de reservas.

Outros autores também observaram efeito negativo da salinidade da água sobre as alturas das plântulas de moringa. Oliveira et al. (2009), avaliando o efeito do estresse salino, com níveis variando de 0,0 a 5,0 dS m-1, sobre o crescimento de plântulas de moringa, obtiveram redução de $74 \%$ nas plântulas irrigadas com água de 
A.

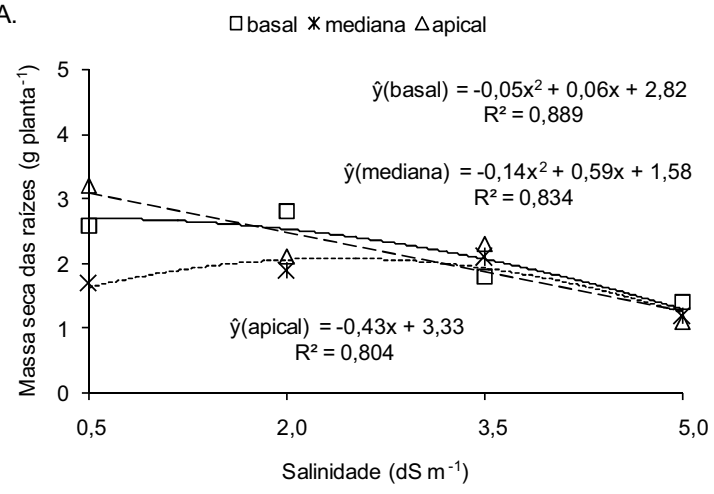

C.

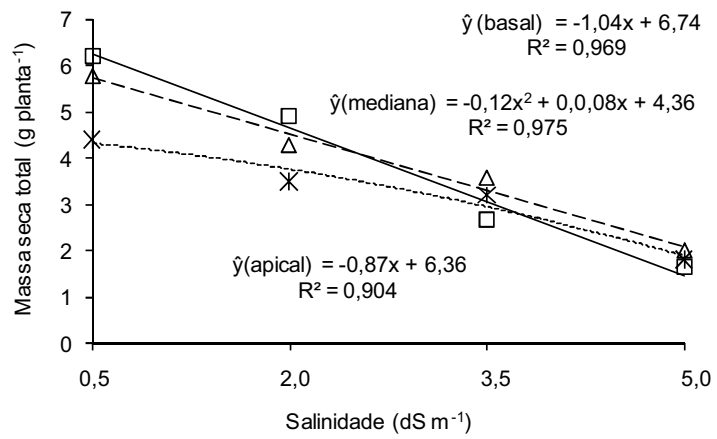

B.

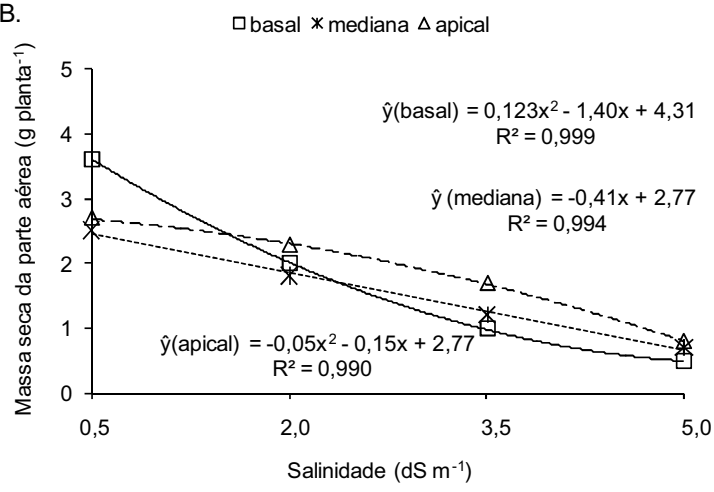

D.

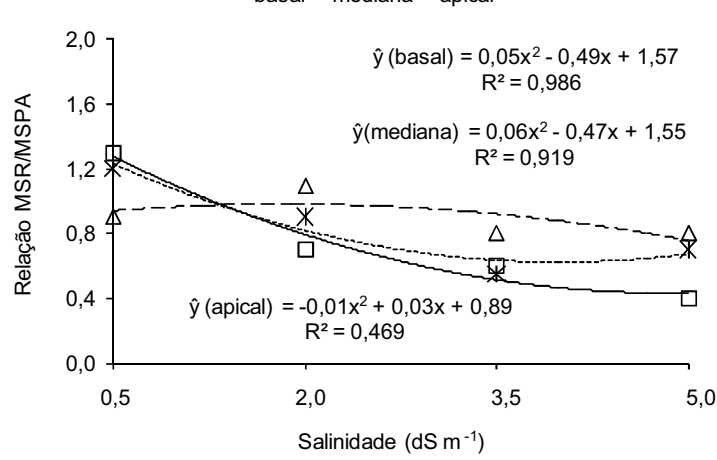

Figura 2 - Massa seca das raízes (A), massa seca da parte aérea (B), massa seca total (C) e relação MSR/MSPA (D) de mudas de moringa provenientes de sementes de diferentes posições no fruto e irrigadas com águas de diferentes níveis de salinidade (— basal, - mediana, _ - apical).

Figure 2 - Root dry mass $(A)$, shoot dry mass $(B)$, total dry mass $(C)$ and MSR/DMAP $(D)$ ratio of moringa seedlings grown from seeds at different positions in the fruit, and irrigated with water at different salinity levels (- basal, median, _- apical).

maior salinidade (5,0 dS m-1). Benedito et al. (2008) também observaram redução significativa na altura de plântulas de moringa em resposta ao estresse salino.

Estudos têm demonstrado que a posição das sementes no fruto pode afetar o crescimento das plantas sob vários aspectos, como vigor e dormência (KIKUTI et al., 2003; NOGUEIRA et al., 2010). Os resultados deste trabalho evidenciaram a importância da seleção de sementes ao longo dos frutos da moringa para se obterem mudas mais vigorosas.

O efeito mais comum da salinidade sobre as plantas é a limitação do crescimento devido ao aumento da pressão osmótica do meio e à consequente redução da disponibilidade de água a ser consumida, afetando a divisão e alongamento das células (MARTINEZ; LAUCHLI, 1994), resultando, consequentemente, em menor desenvolvimento na superfície fotossintética das plantas.
Esse comportamento pode ser atribuído ao fato de as folhas serem responsáveis pela maior transpiração de água pelas plantas. Assim, a redução no número de folhas é provavelmente um artifício adotado pelas plantas para reduzir a transpiração. Outro fator da expressiva redução na emissão de folhas se deve à incapacidade de a planta produzir novas folhas mais rápido que a senescência, além da morte das folhas mais velhas por necrose dos tecidos (MUSCOLO et al., 2003).

Em se tratando de espécie perene, esse fato é de grande importância como mecanismo de tolerância a períodos de deficiência hídrica que frequentemente ocorrem no campo, pois, além da sobrevivência, a maior capacidade de adaptação dessa espécie favorece o crescimento e formação de biomassa em situações de estresse hídrico.

Revista Árvore, Viçosa-MG, v.37, n.1, p.79-87, 2013 
O sistema radicular está diretamente em contato com o meio salino, o que possivelmente pode tornálo mais suscetível às condições adversas do meio de cultivo. No entanto, segundo Shannon (1997), as raízes são diretamente expostas aos ambientes salinos, mas seu crescimento é menos afetado que a parte aérea, aumentando, assim, a relação MSR/MSPA. De acordo com Morales et al. (2001), nem todas as partes das plantas são igualmente afetadas pela salinidade, bem como a adaptação ao estresse salino varia entre espécies e, em um mesmo genótipo, pode variar entre estádios fenológicos.

Segundo Munns (2002), redução no crescimento de plantas sob estresse salino deve-se ao efeito osmótico, associado à toxidez de íons pela absorção excessiva de $\mathrm{Na}$ e $\mathrm{Cl}$ e ao desequilíbrio nutricional causado pelos distúrbios na absorção e, ou, distribuição dos nutrientes.

A adoção de sementes da posição apical, por proporcionarem maior tolerância à salinidade quanto à relação MSR/MSPA, pode ser alternativa para produção de mudas em situações em que o uso de água salina seja inevitável, visto que, conforme Augusto et al. (2007), mudas com elevada razão raiz/parte aérea pode representar uma característica desejável para maior equilíbrio mecânico das mudas em condições de campo.

\section{CONCLUSÕES}

Nas condições em que foi realizado este estudo, pode-se concluir que:

A salinidade da água de irrigação afeta negativamente o crescimento de mudas de moringa, mas a intensidade do efeito é variável em razão da posição da semente no fruto.

As sementes provenientes da posição basal ou apical originaram mudas mais vigorosas que as sementes localizadas na porção mediana.

As mudas provenientes de sementes localizadas na porção basal do fruto são mais afetadas pela salinidade da água de irrigação.

As variáveis de crescimentos mais afetadas pela salinidade são a área foliar e a fitomassa.

Revista Árvore, Viçosa-MG, v.37, n.1, p.79-87, 2013

\section{REFERÊNCIAS}

AUGUSTO, D. C. C. et al. Utilização de águas residuárias provenientes do tratamento biológico de esgotos domésticos na produção de mudas de Eucalyptus grandis Hill. ex. Maiden. Revista Árvore, v.31, n.4, p.745-751, 2007.

BENEDITO, C. P.; RIBEIRO, M. C.; TORRES, S. B. Salinidade na germinação de semente e no desenvolvimento das plântulas de moringa (Moringa Oleifera Lam.). Revista Ciência Agronômica, v.39, n.3, p.463-467, 2008.

BEZERRA, A. M. E.; MOMENTÉ, V. G.; MEDEIROS FILHO, S. Germinação de sementes e desenvolvimento de plântulas de moringa (Moringa oleifera Lam.) em função do peso da semente e do tipo de substrato. Horticultura Brasileira, v.22, n.2, p.295-299, 2004.

BIRUEL, P. R.; PAULA, R. C.; AGUIAR, I. B. Germinação de sementes de Caesalpinia leiostachya (benth.) Ducke (pau-ferro) classificadas pelo tamanho e pela forma. Revista Árvore, v.34, n.2, p.197-204, 2010.

CARVAlho, N. M.; NAKAGAWA, J. Sementes: ciência, tecnologia e produção. 4.ed. Jaboticabal: FUNEP, 2000. 588p.

EMPRESA BRASILEIRA DE PESQUISA AGROPECUÁRIA - EMBRAPA. Manual de métodos de análises de solo. 2.ed. Rio de Janeiro, Ministério da Agricultura e do Abastecimento, 1997. 212p

KIKUTI, A. N. P. et al. Desempenho de sementes de milho em relação à sua localização na espiga. Ciência e Agrotecnologia, v.27, n.4, p.765-770, 2003.

LOREnZI, H.; MATOS, F. J. A. Plantas

medicinais no Brasil: nativas e exóticas cultivadas. Nova Odessa: Instituto Plantarum, 2002. 347 p.

MARCOS FILHO, J. Fisiologia de sementes de plantas cultivadas. Piracicaba: FEALQ, 2005. 495p. 
MARTINEZ, V.; LÄUCHLI, A. Salt-induced of phosphate uptake in plants of cotton (Gossypium hirsutum L.). New Phytologist, v.125, n.4, p.609-614, 1994.

MORALES, M. A. et al. Differences in water relations, leaf ion accumulation and excretion rates between cultivated and wild species of Limonium sp. grown in conditions of saline stress. Flora, v. 196, n.5, p.345-352, 2001.

MUNIZZI, A. et al. Qualidade de sementes de quatro cultivares de soja, colhidas em dois locais no estado de Mato Grosso do Sul. Revista Brasileira de Sementes, v.32, n.1, p.176-185, 2010.

MUNNS, R. Comparative physiology of salt and water stress. Plant Cell Environmet, v.25, p.239-250, 2002.

MUSCOLO, A.; PANUCCIO, M. R.; SIDARI, M. Effects of salinity on growth, carbohydrate metabolism and nutritive properties of kikuyu grass (Pennisetum clandestinum Hoscht). Plant Science, v.164, n.6, p.1103-1110, 2003.
NIETSCHE, S. et al. Tamanho da semente e substratos na germinação e crescimento inicial de mudas de cagaiteira. Ciência e Agrotecnologia, v.28, n.6, p.1321-1325, 2004.

NOGUEIRA, N. W. et al. Grau de dormência das sementes de jucá em função da posição na vagem. Revista Verde de Agroecologia e Desenvolvimento Sustentável, v.5, n.1, p.39-42, 2010.

OLIVEIRA, F. R. A. et al. Emergência de plântulas de moringa irrigada com água de diferentes níveis de salinidade. Bioscience Journal, v.25, n.5, p.66-74, 2009.

SHANNON, M.C. Genetics of salt tolerance in higher plants. In: JAIWAL, P. K.; SINGH, R. P.; GULATI, A. (Ed.). Strategies for improving salt tolerance in higher plants. Oxford: BIJ, 1997. p.265-289.

ZUCHI, J. et al. Qualidade fisiológica de sementes de mamona classificadas por tamanho. Revista Brasileira de Sementes, v.32, n.3, p.177-183, 2010. 
